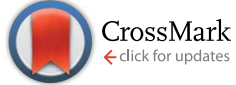

Cite this: Energy Environ. Sci., 2014, 7, 2974

Received 14th June 2014 Accepted 9th July 2014

DOI: $10.1039 / c 4 e e 01842 g$

www.rsc.org/ees

\section{Reducing burn-in voltage loss in polymer solar cells by increasing the polymer crystallinity $\dagger$}

\author{
Thomas Heumueller, ${ }^{\text {ab }}$ William R. Mateker, ${ }^{a}$ I. T. Sachs-Quintana, ${ }^{a}$ Koen Vandewal, ${ }^{a}$ \\ Jonathan A. Bartelt, ${ }^{,}$Timothy M. Burke, ${ }^{a}$ Tayebeh Ameri, ${ }^{\text {b }}$ Christoph J. Brabec ${ }^{\text {bc }}$ \\ and Michael D. McGehee ${ }^{\star a}$
}

In order to commercialize polymer solar cells, the fast initial performance losses present in many high efficiency materials will have to be managed. This burn-in degradation is caused by light-induced traps and its characteristics depend on which polymer is used. We show that the light-induced traps are in the bulk of the active layer and we find a direct correlation between their presence and the open-circuit voltage loss in devices made with amorphous polymers. Solar cells made with crystalline polymers do not show characteristic open circuit voltage losses, even though light-induced traps are also present in these devices. This indicates that crystalline materials are more resistant against the influence of traps on device performance. Recent work on crystalline materials has shown there is an energetic driving force for charge carriers to leave amorphous, mixed regions of bulk heterojunctions, and charges are dominantly transported in pure, ordered phases. This energetic landscape allows efficient charge generation as well as extraction and also may benefit the stability against light-induced traps.

\section{Introduction}

Organic bulk heterojunction solar cells recently surpassed efficiencies of $10 \% .^{\mathbf{1}, 2}$ The stability of organic solar cells is also of significant importance. ${ }^{3-5}$ Recent investigations on several high performing materials for organic solar cells showed severe efficiency losses of up to $25 \%$ during the initial phase of operation. ${ }^{6-9}$ For electronic devices with fast initial failure, a burnin $^{\mathbf{1 0}}$ step is often performed by the manufacturer to provide a more reliable product to the customer. Referring to this practice, the initial degradation in OPV devices has been termed a "burn-in"7 period. This burn-in degradation is a severe limitation for the efficiency of organic photovoltaic modules.

${ }^{a}$ Department of Materials Science and Engineering, Stanford University, Stanford, CA 94305, USA. E-mail: mmcgehee@stanford.edu

${ }^{b} I M E E T$, Friedrich-Alexander-Universität Erlangen-Nürnberg (FAU), Erlangen, Germany

${ }^{c}$ Bayerisches Zentrum für Angewandte Energieforschung, Erlangen, Germany

$\dagger$ Electronic supplementary information (ESI) available. See DOI: 10.1039/c4ee01842g

\section{Broader context}

Organic photovoltaics (OPV) are a promising technology with the potential for large scale production at very low cost. An industrial application of this technology could significantly contribute to the global energy production, but was impeded by low efficiencies and lifetimes of organic photovoltaics. With power conversion efficiencies recently surpassing $10 \%$, it is now imperative to investigate and improve the lifetime of polymerfullerene solar cells. The lifetime of OPV can depend on many variables and results between different laboratories are sometimes difficult to compare. We show how to distinguish multiple simultaneously occurring degradation mechanisms and how to identify their influence on different device parameters. We find that a high degree of crystallinity significantly reduces the initial light induced burn-in degradation which provides a general design rule for organic solar cells.

Understanding and limiting the burn-in losses will be a crucial step toward commercialization of organic photovoltaics.

Several different degradation mechanisms of organic solar cells can be distinguished. Besides extrinsic factors like reactions with oxygen, ${ }^{\mathbf{1 1} 12}$ intrinsic reactions are of high importance, as they limit the stability of encapsulated devices. Interface degradation is well studied for metal electrodes and PEDOT:PSS, ${ }^{3}$ but more research has to be done on solution processable metal oxide contact materials. ${ }^{13}$ Another important mechanism is thermal degradation, which occurs above the glass transition temperature $\left(T_{\mathrm{g}}\right)$ of a polymer and induces morphological changes like phase separation. ${ }^{\mathbf{1 4}}$ For polymers with low $T_{\mathrm{g}}$, like P3HT, thermal degradation can be observed at typical solar cell operating conditions. ${ }^{15}$ In light ageing experiments below the $T_{\mathrm{g}}$ of PCDTBT no morphological changes were observed in X-ray diffraction experiments. ${ }^{6}$ Finally, lightinduced degradation is highly important, since solar cells operate under relatively high photon fluxes. Recent research has proposed both general mechanisms for light-induced degradation in all polymers ${ }^{\mathbf{1 6 , 1 7}}$ and more specific reactions ${ }^{\mathbf{1 8 , 1 9}}$ in various materials, including crosslinking ${ }^{20}$ and fullerene dimerization. ${ }^{21}$ A conclusive explanation of the mechanisms behind light-induced degradation, however, is still missing. 
Detailed studies on burn-in have been made on PCDTBT: PC $_{70}$ BM solar cells. ${ }^{6}$ In this system, a fast initial loss of $20 \%$ efficiency is followed by a slow linear degradation regime yielding lifetimes over 6 years. ${ }^{7}$ Characteristic for the burn-in losses in PCDTBT is a significant reduction in the open circuit voltage $\left(V_{\mathrm{oc}}\right)$ of the solar cells. These losses are caused by a lightinduced reaction, as the $V_{\mathrm{oc}}$ is stable at operating temperatures of $50{ }^{\circ} \mathrm{C}$ in the dark. ${ }^{6}$ For P3HT:PCBM solar cells, however, no fast initial $V_{\mathrm{oc}}$ loss is observed. ${ }^{7}$ This distinct difference between P3HT and PCDTBT has not yet been explained. A major difference between P3HT and PCDTBT is the polymer morphology. Specifically, P3HT is a crystalline material and PCDTBT is largely amorphous. ${ }^{22}$

Thus, we chose to study the impact of morphology on the light-induced burn-in of organic solar cells. Recent work by several groups has brought a paradigm shift in understanding the morphology of organic solar cells and its implications for device performance. ${ }^{23-29}$ In addition to pure fullerene and pure polymer phases, an amorphous, mixed phase was found in BHJs made with crystalline polymers and the mixed phase is suggested to be a key factor for charge separation. ${ }^{27,30}$ After charge separation, the free electrons and holes are transported through the pure donor and acceptor phases, respectively, which spatially separate electrons and holes. ${ }^{23}$ We hypothesize that such spatial separation of electrons and holes leads to the increased stability of crystalline materials against the influence of light-induced traps on the solar cell performance.

We compare the light-induced degradation in solar cells using crystalline and amorphous polymers. While the amorphous polymers show significant burn-in losses of $\approx 15 \%$ within 60 hours, the crystalline polymers only lose $\approx 5 \%$ efficiency (Fig. 1). Measurements of the trap distribution by a transient photocurrent technique show traps in both amorphous and crystalline polymers. This finding suggests that crystalline polymers are more stable against $V_{\mathrm{oc}}$ losses due to light-induced traps.

\section{Selecting crystalline and amorphous materials}

In order to compare the burn-in degradation in crystalline and amorphous materials, we chose (regioregular) P3HT and KP115 (ref. 31 and 32) as crystalline polymers and PCDTBT ${ }^{33}$ and regiorandom (RRa) P3HT as amorphous polymers. The power conversion efficiency losses during burn-in show significant differences between amorphous and crystalline polymers (Fig. 1). Annealed P3HT has a degree of crystallinity near 50\% (ref. 34) and regiorandom P3HT is amorphous. ${ }^{35}$ Thus, the comparison between (regioregular) P3HT and RRa P3HT is powerful, as they have the same chemistry and differences between these two materials are only caused by their morphology. With PCDTBT and KP115 we compare two high efficiency "donor-acceptor" polymers.

KP115 allows active layers up to $400 \mathrm{~nm}$ thickness without fill factor loss, ${ }^{31}$ but its morphology is not well studied. Using X-ray diffraction and absorption measurements we show a relatively high degree of crystallinity for this polymer (Fig. 2a). Our grazing incidence X-ray diffraction measurements show four distinguishable orders of the lamellar peak for KP115 (see ESI $\dagger$ for peak fits). In contrast, X-ray diffraction measurements of PCDTBT, a mainly amorphous material, reveal only one crystalline peak (Fig. 2b). This finding clearly shows that KP115 has more crystalline order than PCDTBT, which can further be observed in optical absorption spectra. While fully dissolved KP115 in a hot dichlorobenzene (DCB) solution shows one absorption peak with an onset of absorption around $600 \mathrm{~nm}$, the absorption spectrum of KP115 in thin films is significantly redshifted with an absorption edge around $680 \mathrm{~nm}$ (Fig. 2c). This redshift is caused by increased delocalization due to crystallization of polymer chains. Further, two pronounced vibronic peaks $^{34}$ are present in the thin film indicating its high degree of interchain order. For the measurement in solution, heating to $140{ }^{\circ} \mathrm{C}$ was necessary to avoid this aggregation and the occurrence of vibronic peaks already in solution. PCDTBT is largely
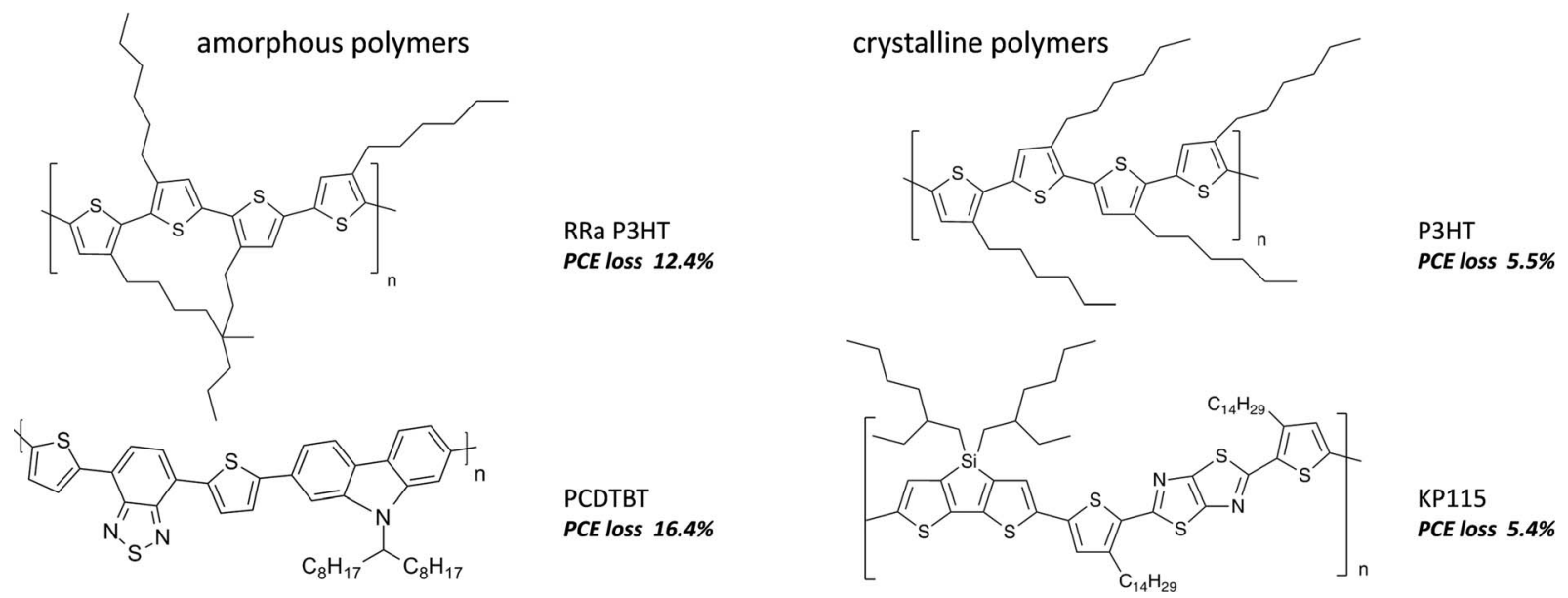

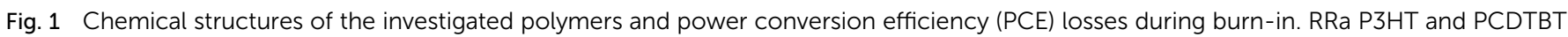
are amorphous, P3HT and KP115 are crystalline. 

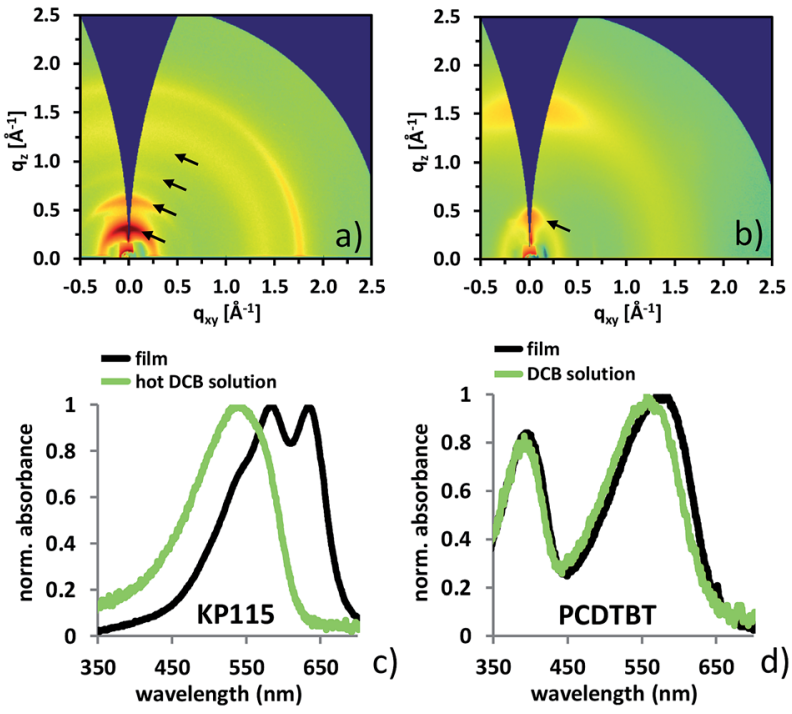

Fig. 2 XRD-patterns of KP115 (a) showing four orders of the lamellar peak, and PCDTBT (b) with only a first order peak. Absorption measurements of KP115 (c) in hot solution (blue) and a solid film (black) reveal a strong redshift for the solid state and vibronic peaks indicating a high degree of crystallinity for this material. No significant redshift is observed for PCDTBT absorption measurements (d).

amorphous and the absorption spectrum of thin films does not show a significant redshift from solution absorption nor the presence of distinct vibronic peaks (Fig. 2d).

\section{Solar cell degradation}

\subsection{Experimentally isolating light-induced degradation}

We performed burn-in degradation experiments with one sun equivalent illumination intensity for $\approx 60$ hours on all four polymers investigated in this study. The solar cells were fabricated in a glovebox and aged under high vacuum, excluding the well-known effects of oxygen degradation ${ }^{3,12,36-39}$ from our experiments. Furthermore, the cells were cooled to $27{ }^{\circ} \mathrm{C}$ to prevent thermal degradation mechanisms that can occur in polymers with a low glass transition temperature $\left(T_{\mathrm{g}}\right)$ such as P3HT $\left(T_{g}=56{ }^{\circ} \mathrm{C}\right) \cdot{ }^{15}$ It is important to operate all cells at temperatures below their $T_{\mathrm{g}}$ to avoid thermally induced morphological changes. ${ }^{6,14}$ However, even for a controlled substrate temperature, the active layer was observed to be up to $12{ }^{\circ} \mathrm{C}$ hotter than the substrate under illumination, see ESI. $\dagger$ This temperature increase could not only activate thermal degradation, but also cause a reversible, temperature-dependent $V_{\text {oc }}$ change on the timescale of several minutes. We minimized this effect by using white light LED's. To exclude any other influence of the experimental conditions on the results, one crystalline and one amorphous polymer were aged in the same test side by side. Another degradation mechanism we exclude in this work is fast initial short-circuit current loss in KP115: $\mathrm{PC}_{60} \mathrm{BM}$ solar cells ${ }^{9}$ that was proposed to be caused by light-induced fullerene dimerization. ${ }^{21}$ By using $\mathrm{PC}_{70} \mathrm{BM}$ in our KP115 solar cells, we inhibit this loss mechanism because $\mathrm{C}_{70}$ cages have a lower susceptibility to dimerization. ${ }^{40}$

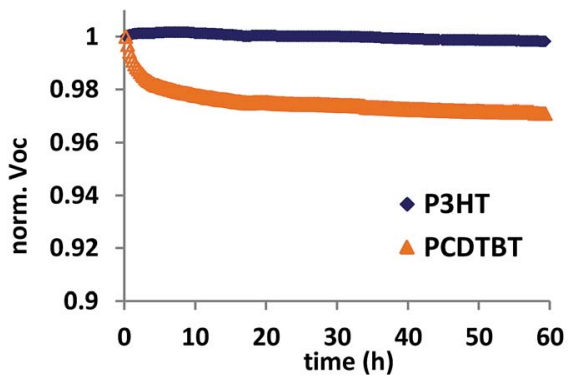

a)

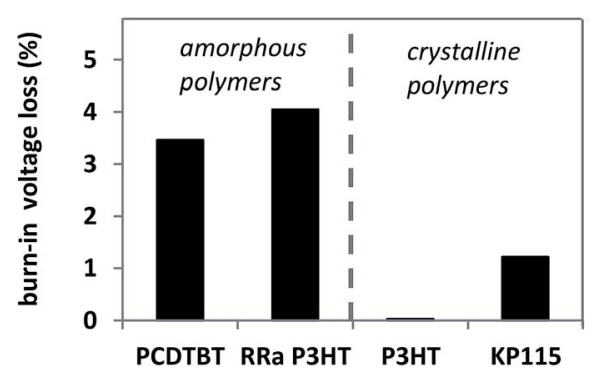

b)

Fig. 3 Normalized open circuit voltage losses over illumination time for PCDTBT and P3HT solar cells (a) and data measured with a solar simulator before and after burn-in for amorphous and crystalline materials (b).

The investigated solar cells were built in a standard device architecture with PEDOT:PSS and calcium-aluminum contacts and the starting efficiencies were $5.4 \%$ (PCDTBT), $1.5 \%$ (RRaP3HT), 4.4\% (P3HT) and 5.2\% (KP115). For more details see ESI. $\dagger$

\subsection{Only amorphous polymers significantly lose open circuit voltage}

The current-voltage measurements taken before and after aging show a clear trend: The two amorphous polymers, PCDTBT and RRa P3HT, lose $\approx 15 \%$ efficiency after aging for 60 hours, while the crystalline polymers, P3HT and KP115, lose only $\approx 5 \%$ efficiency (Fig. 1). Intriguingly, the more stable crystalline materials have barely lost any open circuit voltage, whereas the amorphous materials show a $V_{\text {oc }}$ drop of around $4 \%$ (Fig. 3). This result is very reproducible for PCDTBT, KP115 and P3HT, for RRa P3HT the reproducibility is only around $70 \%$, since device fabrication shows some inconsistencies with this material. The short circuit current losses in all materials are $1-2 \%$, and the fill factor decreases by $2-3 \%$ for crystalline materials and $8-12 \%$ for amorphous materials.

\subsection{Reapplying new electrodes distinguishes bulk and interface degradation}

Peeling the metal electrodes off organic solar cells and reapplying new ones is a powerful tool to isolate effects related to the metal-organic interface. ${ }^{41,42}$ We find that with freshly-applied electrodes, aged PCDTBT devices retain their reduced $V_{\mathrm{oc}}$ (Fig. 4). Consequently the loss of open circuit voltage does not depend on the metal-organic interface. This finding suggests that light-induced traps in the bulk of the active layer are 
responsible for the decreased $V_{\text {oc }}$. In contrast, most of the fill factor losses in aged devices are restored with new electrodes. Consequently, the reduced fill factor is related to degradation at the metal-organic interface. A possible mechanism for the fill factor loss may be the formation of an extraction barrier at the organic-calcium interface. Since the open circuit voltage losses are observed to be a symptom of changes in the active layer, we focus on this device parameter in the present study.

\section{Measuring traps in aged solar cells}

\subsection{Light-induced traps form in all investigated materials}

Reduced open circuit voltage in organic solar cells is thought to be caused by the formation of localized trap states, facilitating trap assisted recombination. ${ }^{\mathbf{4 3 4}}$ Since our aging experiments showed $V_{\text {oc }}$ losses only in the amorphous materials, one might suspect that traps form only in these materials, but not in crystalline materials. To test this hypothesis, measurements of the trap distribution in devices are necessary. Shuttle et al. recently demonstrated a powerful transient photocurrent technique that determines the trap density and distribution in organic solar cells. ${ }^{45}$ A short laser pulse creates charge carriers in the solar cell, and the current response is recorded over several orders of magnitude after the light has been turned off. Carriers leaving the device on the microsecond timescale are mobile or reside for short times in shallow traps, while carriers leaving at longer timescales originate from traps of increasing depth. Each carrier has the same attempt frequency to leave its trap but the probability of escaping the trap decreases with increasing trap depth. Consequently, on average it takes longer for a carrier to leave a deeper trap, and current on long timescales can be seen from deep traps. The capability of this technique was confirmed by artificially introducing $\mathrm{C}_{60}$ as an electron trap into P3HT:PCBM solar cells (ESI $\dagger$ ).

The transient photocurrent measurements before and after aging are shown in Fig. 5. An increase of the current signal from traps around $100 \mu \mathrm{s}$ is observed for aged devices of all polymers. This finding indicates the formation of localized states under light exposure in all polymers, not only in the amorphous

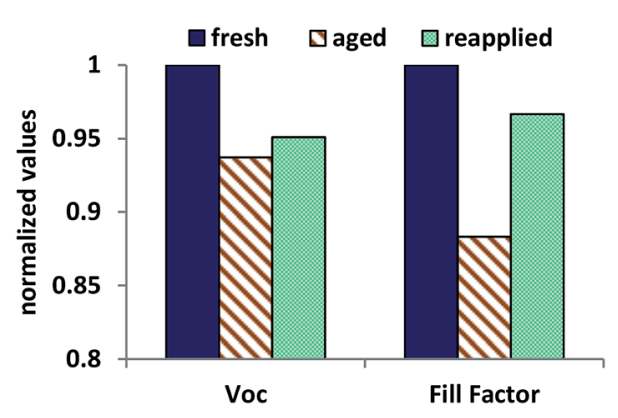

Fig. 4 Open circuit voltage and fill factor of an aged PCDTBT device before and after reapplying new electrodes, as well as for the pristine cell. The open circuit voltage it is unchanged with new electrodes which suggests a bulk effect. In contrast, the fill factor is mainly restored with new electrodes indicating degradation at the metalorganic interface. materials. However, only in amorphous polymers is the device $V_{\text {oc }}$ reduced upon illumination. The crystalline polymers even show a slightly stronger increase in photocurrent than the amorphous materials. This finding may mean that slightly more traps form during degradation, or that the better charge transport in the crystalline materials allows more efficient extraction of charge carriers once they leave a trap.

While light-induced traps are present in crystalline materials, the open circuit voltage is not reduced. This suggests an increased stability of crystalline materials against performance losses by light-induced traps.

\subsection{Distinguishing bulk and interface traps}

By reapplying new electrodes on aged devices, we correlate $V_{\mathrm{oc}}$ losses to light-induced traps in the bulk and distinguish these traps from those at the metal-organic interface. The transient photocurrent measurements on an aged PCDTBT device before and after reapplying new electrodes are compared to the measurement of the pristine cell before aging. The clear increase of photocurrent around $100 \mu \mathrm{s}$ in the aged device is still visible with new electrodes (Fig. 6). Consequently, this effect reflects properties of the bulk material and is electrode independent. This is in perfect congruence with the electrode independent $V_{\text {oc }}$ losses (Fig. 4). Further, the fact that those traps are light induced suggests that they are present throughout the entire active layer.

Distinguishable from this bulk effect, interface degradation is also observed by the transient photocurrent increase in the range of tens of microseconds. In contrast to traps in the bulk, this signal is reduced back to the curve of the fresh cell with new electrodes. As the electrode is replaced, most of the fill factor is also restored (Fig. 4). This observation shows clearly that

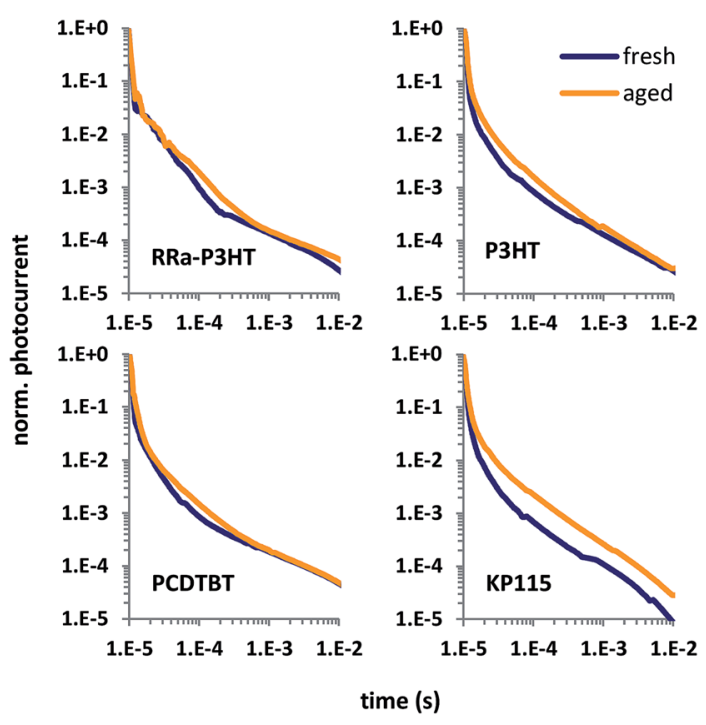

Fig. 5 Observed transient photocurrents for RRa-P3HT, P3HT, PCDTBT and KP115 solar cells show a signal increase around $100 \mu \mathrm{s}$ after aging in all polymers. This indicates the formation of lightinduced traps during burn-in. A $405 \mathrm{~nm}$ diode laser turned off at $10 \mu \mathrm{s}$ is used as light source. 


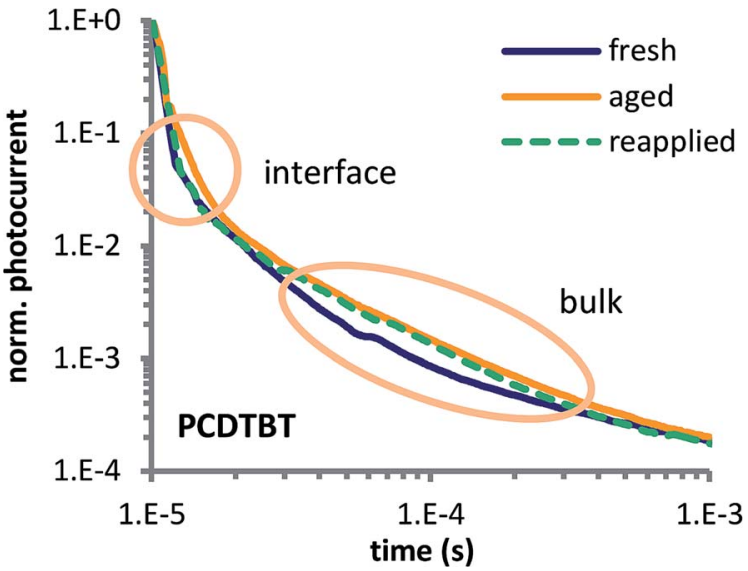

Fig. 6 Transient photocurrent measurements of an aged PCDTBT device before and after reapplying new electrodes, as well as for the pristine cell (left). The signal around $100 \mu$ s shows a clear correlation with $V_{\text {oc }}$ of the device (Fig. 4) and is related to a bulk effect, since it is unchanged with new electrodes. The increased signal due to interface degradation can be eliminated with new contacts.

interface degradation is occurring in the PCDTBT solar cells and causes additional fill factor losses. These fill factor losses may be related to an extraction barrier forming at the organiccalcium interface, but further investigation of this effect is beyond the scope of this study.

To verify that the PEDOT:PSS electrode is not affecting the photocurrent transients, we constructed devices with a $\mathrm{MoO}_{x}$ bottom contact. The transient photocurrent signal of fresh and aged devices behave the same as for PEDOT:PSS devices (ESI $\dagger$ ). This finding further verifies that the increased photocurrent at $100 \mu \mathrm{s}$ in the transients is from light-induced traps in the active layer and not from interfacial effects at the electrodes.

\section{Discussion}

Considering the absence of light-induced $V_{\text {oc }}$ losses in crystalline polymers, we propose that the specific morphology of those materials, which leads to efficient charge separation and extraction, also provides an increased stability against performance losses through light-induced traps. Recent work draws the following morphological picture of a bulk heterojunction solar cell. The high miscibility of fullerenes in organic semiconductors results in the presence of amorphous, mixed pha$\operatorname{ses}^{\mathbf{2 8 , 2 9 , 4 6}}$ in which charge separation occurs at donor-acceptor interfaces. Percolating pathways of polymer chains and fullerenes within the mixed phase allow holes and electrons to migrate out of the mixed phase and into the aggregated polymer and fullerene phases, respectively. ${ }^{23,27}$ These larger, pure phases provide efficient charge transport throughout the bulk heterojunction towards the contacts. ${ }^{23,47,48}$ An energetic offset between the amorphous and crystalline phases ${ }^{\mathbf{2 6 , 4 9}}$ likely causes electrons and holes to stay in their respective pure phases, in which they are transported very efficiently. ${ }^{47}$ In such a three phase system, recombination is expected only if electrons and holes meet each other in the mixed phase. However, to re-enter the mixed phase and recombine, electrons and holes must overcome an energetic barrier. In contrast to crystalline materials, amorphous materials consist of mostly mixed phase. ${ }^{46}$ In such an environment, electrons and holes are present and transported in the same (mixed) phase which may lead to increased non-geminate recombination. The detailed mechanisms of how these differences in device operation between crystalline and amorphous materials impact their sensitivity to traps are still under investigation. It is conceivable that the spatial separation of electrons and holes in crystalline materials may reduce a possibly trap-assisted recombination. However, differences in charge carrier density or energetic disorder between crystalline and amorphous materials could also explain the different influence of light-induced traps.

\section{Conclusions}

Light-induced, bulk traps are formed in both crystalline and amorphous materials as revealed by transient photocurrent measurements. Only amorphous materials show a decreased $V_{\text {oc }}$ after aging. Crystalline materials show less burn-in losses.

These findings may have general implications for the development of organic solar wells with improved stability. A high degree of crystallinity could reduce the impact of lightinduced traps on device performance by a spatial separation of electrons and holes. Moreover, a high degree of crystallinity also seems to reduce photo-oxidation in unencapsulated polymer films ${ }^{37}$ suggesting that crystalline materials may be more stable under various conditions.

By reapplying new electrodes to aged devices we distinguished bulk and interface degradation that affect solar cell performance in a different way. Our findings can be a reminder that different degradation mechanisms proposed in literature may not exclude, but rather complement each other and more effort has to be made distinguishing simultaneously occurring degradation mechanisms.

\section{Experimental section}

\subsection{Device preparation}

The solar cells used in this work have a classical device architecture with a PEDOT:PSS (Clevios P VP AI 4083) hole extraction layer spin coated on cleaned ITO substrates $(15 \Omega$ per sq, Xinyan Technologies LTD). The substates were ultasonicated with Extran 300 detergent (diluted 1:9 in water), rinsed in deionized water and ultrasonicated for $15 \mathrm{~min}$ each in acetone and isopropyl alcohol before a $15 \mathrm{~min}$ UV-ozone treatment. The active layers are spin cast from a dichlorobenzene solution and dried slowly in a closed Petri dish overnight to achieve a high degree of crystallinity for the P3HT and KP115 solar cells. The P3HT cells are annealed at $110{ }^{\circ} \mathrm{C}$ for 10 minutes before electrode deposition, KP115 cells at $80{ }^{\circ} \mathrm{C}$ after electrode deposition. On all cells a calcium $(7 \mathrm{~nm}) /$ aluminum $(150 \mathrm{~nm})$ top contact is thermally evaporated at $\approx 10^{-6}$ Torr. In both amorphous materials the optimum polymer to fullerene ratio of $1: 4$ is used to accommodate the high solubility of fullerene in amorphous phases. For lower fullerene contents electron transport is 
usually insufficient in amorphous materials. In the crystalline materials a polymer to fullerene ratio of $1: 1$ is sufficient to achieve good electron transport since no fullerene is dissolved in the crystalline domains. $\mathrm{PC}_{70} \mathrm{BM}$ was used in all solar cells, except in $\mathrm{P} 3 \mathrm{HT}$, where typically $\mathrm{PC}_{60} \mathrm{BM}$ is used. ${ }^{50}$ Both fullerenes were purchased from Solenne BV, P3HT was purchased from BASF (P200), RRa P3HT from Rieke, PCDTBT was received from St. Jean Photochemie and KP115 from Konarka. The total active layer solution concentrations for the used, optimized devices were $50 \mathrm{mg} \mathrm{ml}^{-1}$ (P3HT), $40 \mathrm{mg} \mathrm{ml}^{-1}$ (KP115), $25 \mathrm{mg}$ $\mathrm{ml}^{-1}$ (RRa P3HT) and $20 \mathrm{mg} \mathrm{ml}^{-1}$ (PCDTBT). The efficiencies of the prepared devices shown in the supplemental are comparable to results published on good solar cells of the respective materials. $^{31,33,50}$

\subsection{Degradation experiments}

The LED illumination was adjusted to match the short circuit current $\left(J_{\mathrm{sc}}\right)$ with the value recorded under a solar simulator at AM 1.5 G. All experiments were performed in a liquid nitrogen cryostat under high vacuum conditions, the cells were loaded into the cryostat directly inside the glovebox and never exposed to oxygen. IV curves were recorded periodically every $15 \mathrm{~min}$ with a Keithley 2400 source measure unit. The temperature was held at $27{ }^{\circ} \mathrm{C}$ using a Lakeshore temperature controller.

\subsection{Transient photocurrent measurements}

A $405 \mathrm{~nm}$ laser diode driven by a function generator was used to generate $10 \mu$ s light pulses. The current response was amplified with a transimpedance amplifier and recorded with a digital oscilloscope. Changing the feedback resistor of the amplifier allows recording the signal over several orders of magnitude with amplifications form $10 \times$ to $10^{7} \times$. The individual curves at different amplifications were stitched together.

\section{Acknowledgements}

The authors acknowledge Prof. Alberto Salleo and Duc T. Duong for helpful discussions. TH gratefully acknowledges a "DAAD Doktorantenstipedium" and the SFB 953 "Synthetic Carbon Allotropes". This publication was supported by the Center for Advanced Molecular Photovoltaics (CAMP) (Award no. KUS-C1015-21), made by King Abdullah University of Science and Technology (KAUST). CJB acknowledges funding from the Cluster of Excellence "Engineering of Advanced Materials", the Bavarian SolTech initiative and the GRK 1896 "in situ microscopy”. JAB acknowledges government support by the Department of Defense (DoD) through the National Defense Science \& Engineering Graduate Fellowship (NDSEG) Program.

\section{References}

1 J. You, L. Dou, K. Yoshimura, T. Kato, K. Ohya, T. Moriarty, K. Emery, C.-C. Chen, J. Gao, G. Li and Y. Yang, Nat. Commun., 2013, 4, 1446.

2 M. A. Green, K. Emery, Y. Hishikawa, W. Warta and E. D. Dunlop, Prog. Photovoltaics, 2013, 21, 827-837.
3 M. Jørgensen, K. Norrman, S. a. Gevorgyan, T. Tromholt, B. Andreasen and F. C. Krebs, Adv. Mater., 2012, 24, 580-612. 4 N. Grossiord, J. M. Kroon, R. Andriessen and P. W. M. Blom, Org. Electron., 2012, 13, 432-456.

5 G. Griffini, J. D. Douglas, C. Piliego, T. W. Holcombe, S. Turri, J. M. J. Fréchet and J. L. Mynar, Adv. Mater., 2011, 23, 1660-1664.

6 C. H. Peters, I. T. Sachs-Quintana, W. R. Mateker, T. Heumueller, J. Rivnay, R. Noriega, Z. M. Beiley, E. T. Hoke, A. Salleo and M. D. McGehee, Adv. Mater., 2012, 24, 663-668.

7 C. H. Peters, I. T. Sachs-Quintana, J. P. Kastrop, S. Beaupré, M. Leclerc and M. D. McGehee, Adv. Energy Mater., 2011, 1, 491-494.

8 R. Roesch, K.-R. Eberhardt, S. Engmann, G. Gobsch and H. Hoppe, Sol. Energy Mater. Sol. Cells, 2013, 117, 59-66.

9 T. M. Clarke, C. Lungenschmied, J. Peet, N. Drolet, K. Sunahara, A. Furube and A. J. Mozer, Adv. Energy Mater., 2013, 3, 1473-1483.

10 P.-H. Lee, C.-C. Torng and Y.-C. Lin, Appl. Math. Model., 2011, 35, 4023-4030.

11 E. T. Hoke, I. T. Sachs-Quintana, M. T. Lloyd, I. Kauvar, W. R. Mateker, A. M. Nardes, C. H. Peters, N. Kopidakis and M. D. McGehee, Adv. Energy Mater., 2012, 2, 13511357.

12 J. Schafferhans, A. Baumann, A. Wagenpfahl, C. Deibel and V. Dyakonov, Org. Electron., 2010, 11, 1693-1700.

13 J. You, C.-C. Chen, L. Dou, S. Murase, H.-S. Duan, S. a. Hawks, T. Xu, H. J. Son, L. Yu, G. Li and Y. Yang, Adv. Mater., 2012, 24, 5267-5272.

14 B. Conings, S. Bertho, K. Vandewal, A. Senes, J. D'Haen, J. Manca and R. A. J. Janssen, Appl. Phys. Lett., 2010, 96, 163301.

15 I. T. Sachs-Quintana, T. Heumüller, W. R. Mateker, D. E. Orozco, R. Cheacharoen, S. Sweetnam, C. J. Brabec and M. D. McGehee, Adv. Funct. Mater., 2014, 24, 3978-3985.

16 R. A. Street and D. M. Davies, Appl. Phys. Lett., 2013, 102, 043305.

17 R. Street, J. Northrup and B. Krusor, Phys. Rev. B: Condens. Matter Mater. Phys., 2012, 85, 205211.

18 A. Rivaton, A. Tournebize, J. Gaume, P.-O. Bussière, J.-L. Gardette and S. Therias, Polym. Int., 2013, 63, 13351345.

19 X. Tong, N. Wang, M. Slootsky, J. Yu and S. R. Forrest, Sol. Energy Mater. Sol. Cells, 2013, 118, 116-123.

20 A. Tournebize, P.-O. Bussière, P. Wong-Wah-Chung, S. Thérias, A. Rivaton, J.-L. Gardette, S. Beaupré and M. Leclerc, Adv. Energy Mater., 2013, 3, 478-487.

21 A. Distler, T. Sauermann, H.-J. Egelhaaf, S. Rodman, D. Waller, K.-S. Cheon, M. Lee, N. Drolet and D. M. Guldi, Adv. Energy Mater., 2013, 4, 1300693.

22 Z. M. Beiley, E. T. Hoke, R. Noriega, J. Dacuña, G. F. Burkhard, J. A. Bartelt, A. Salleo, M. F. Toney and M. D. McGehee, Adv. Energy Mater., 2011, 1, 954-962.

23 W. Yin and M. Dadmun, ACS Nano, 2011, 5, 4756-4768.

24 P. Westacott, J. R. Tumbleston, S. Shoaee, S. Fearn, J. H. Bannock, J. B. Gilchrist, S. Heutz, J. deMello, 
M. Heeney, H. Ade, J. Durrant, D. S. McPhail and N. Stingelin, Energy Environ. Sci., 2013, 6, 2756.

25 W. Chen, T. Xu, F. He, W. Wang, C. Wang, J. Strzalka, Y. Liu, J. Wen, D. J. Miller, J. Chen, K. Hong, L. Yu and S. B. Darling, Nano Lett., 2011, 11, 3707-3713.

26 F. C. Jamieson, E. B. Domingo, T. McCarthy-Ward, M. Heeney, N. Stingelin and J. R. Durrant, Chem. Sci., 2012, 3, 485.

27 J. A. Bartelt, Z. M. Beiley, E. T. Hoke, W. R. Mateker, J. D. Douglas, B. A. Collins, J. R. Tumbleston, K. R. Graham, A. Amassian, H. Ade, J. M. J. Fréchet, M. F. Toney and M. D. McGehee, Adv. Energy Mater., 2013, 3, 364-374.

28 B. A. Collins, E. Gann, L. Guignard, X. He, C. R. McNeill and H. Ade, J. Phys. Chem. Lett., 2010, 1, 3160-3166.

29 N. D. Treat, M. A. Brady, G. Smith, M. F. Toney, E. J. Kramer, C. J. Hawker and M. L. Chabinyc, Adv. Energy Mater., 2011, 1, 82-89.

30 T. M. Burke and M. D. McGehee, Adv. Mater., 2013, 1-6.

31 J. Peet, L. Wen, P. Byrne, S. Rodman, K. Forberich, Y. Shao, N. Drolet, R. Gaudiana, G. Dennler and D. Waller, Appl. Phys. Lett., 2011, 98, 043301.

32 T. M. Clarke, J. Peet, P. Denk, G. Dennler, C. Lungenschmied and A. J. Mozer, Energy Environ. Sci., 2012, 5, 5241.

33 S. H. Park, A. Roy, S. Beaupré, S. Cho, N. Coates, J. S. Moon, D. Moses, M. Leclerc, K. Lee and A. J. Heeger, Nat. Photonics, 2009, 3, 297-302.

34 S. T. Turner, P. Pingel, R. Steyrleuthner, E. J. W. Crossland, S. Ludwigs and D. Neher, Adv. Funct. Mater., 2011, 21, 4640-4652.

35 X. Shen, V. V. Duzhko and T. P. Russell, Adv. Energy Mater., 2013, 3, 263-270.

36 J. Schafferhans, A. Baumann, C. Deibel and V. Dyakonov, Appl. Phys. Lett., 2008, 93, 093303.

37 Y. W. Soon, H. Cho, J. Low, H. Bronstein, I. McCulloch and J. R. Durrant, Chem. Commun., 2013, 49, 1291-1293.
38 M. Manceau, E. Bundgaard, J. E. Carlé, O. Hagemann, M. Helgesen, R. Søndergaard, M. Jørgensen and F. C. Krebs, J. Mater. Chem., 2011, 21, 4132.

39 A. Seemann, T. Sauermann, C. Lungenschmied, O. Armbruster, S. Bauer, H.-J. Egelhaaf and J. Hauch, Sol. Energy, 2011, 85, 1238-1249.

40 A. Rao, M. Menon and K. Wang, Chem. Phys. Lett., 1994, 224, 106-112.

41 Q. Wang, Y. Luo and H. Aziz, Appl. Phys. Lett., 2010, 97, 063309.

42 W. R. Mateker, J. D. Douglas, C. Cabanetos, I. T. SachsQuintana, J. A. Bartelt, E. T. Hoke, A. El Labban, P. M. Beaujuge, J. M. J. Fréchet and M. D. McGehee, Energy Environ. Sci., 2013, 6, 2529.

43 G. Garcia-Belmonte and J. Bisquert, Appl. Phys. Lett., 2010, 96, 113301.

44 D. Credgington and J. R. Durrant, J. Phys. Chem. Lett., 2012, 3, 1465-1478.

45 C. G. Shuttle, N. D. Treat, J. D. Douglas, J. M. J. Fréchet and M. L. Chabinyc, Adv. Energy Mater., 2012, 2, 111-119.

$46 \mathrm{H}$. W. Ro, B. Akgun, B. T. O'Connor, M. Hammond, R. J. Kline, C. R. Snyder, S. K. Satija, A. L. Ayzner, M. F. Toney, C. L. Soles and D. M. DeLongchamp, Macromolecules, 2012, 45, 6587-6599.

47 R. Noriega, J. Rivnay, K. Vandewal, F. P. V. Koch, N. Stingelin, P. Smith, M. F. Toney and A. Salleo, Nat. Mater., 2013, 12, 1038-1044.

48 K. Vakhshouri, D. R. Kozub, C. Wang, A. Salleo and E. D. Gomez, Phys. Rev. Lett., 2012, 108, 026601.

49 W. C. Tsoi, S. J. Spencer, L. Yang, A. M. Ballantyne, P. G. Nicholson, A. Turnbull, A. G. Shard, C. E. Murphy, D. D. C. Bradley, J. Nelson and J.-S. Kim, Macromolecules, 2011, 44, 2944-2952.

50 M. T. Dang, L. Hirsch and G. Wantz, Adv. Mater., 2011, 23, 3597-3602. 